\title{
CRP, but not TNF- $\alpha$ or IL-6, decreases after weight loss in patients with morbid obesity exposed to intensive weight reduction and balneological treatment ${ }^{*}$
}

\author{
Danuta ROŚĆ ${ }^{11}$, Przemysław ADAMCZYK ${ }^{1}$, Joanna BOINSKA ${ }^{1}$, \\ Robert SZAFKOWSKI ${ }^{2}$, Irena PONIKOWSKA ${ }^{2}$, Katarzyna STANKOWSKA ${ }^{1}$, \\ Barbara GÓRALCZYK ${ }^{1}$, Barbara RUSZKOWSKA-CIASTEK ${ }^{1}$ \\ $\left({ }^{1}\right.$ Department of Pathophysiology, Faculty of Pharmacy, Nicolaus Copernicus University in Toruń, \\ Collegium Medicum in Bydgoszcz, Bydgoszcz PL 85-094, Poland) \\ $\left({ }^{2}\right.$ Clinic of Balneology and Physical Medicine, Faculty of Health Science, Nicolaus Copernicus University in Torun', \\ Collegium Medicum in Bydgoszcz, Bydgoszcz PL 85-094, Poland) \\ ${ }^{\dagger}$ E-mail: drosc@cm.umk.pl
}

Received Aug. 8, 2014; Revision accepted Mar. 17, 2015; Crosschecked Apr. 9, 2015

\begin{abstract}
Objective: The aim of this study was to evaluate the concentrations of C-reactive protein (CRP), tumor necrosis factor- $\alpha$ (TNF- $\alpha$ ), interleukin-6 (IL-6), and the degree of homeostasis model assessment-insulin resistance (HOMA-IR) in patients with morbid obesity exposed to a three-week low-calorie diet and balneotherapy. Methods: The study included 33 patients (25 females and 8 males; mean age 46 years) with body mass index (BMI) values of $>40 \mathrm{~kg} / \mathrm{m}^{2}$. Evaluations of CRP, IL-6, TNF-a, lipid profile, HOMA-IR, and fasting glucose were carried out before (baseline data) and three weeks after the treatment. The control group consisted of 20 healthy volunteers ( 15 females and 5 males) with a mean age of 39 years and BMI values of $\leq 24.9 \mathrm{~kg} / \mathrm{m}^{2}$. Results: In the blood of patients with morbid obesity we found significantly elevated levels of CRP, TNF- $\alpha$, triglycerides, HOMA-IR and fasting glucose, but a decreased level of high density lipoprotein (HDL)-cholesterol, compared with the healthy individuals. The treatment resulted in about a $9.4 \%$ reduction in body weight from 122.5 to $111.0 \mathrm{~kg}$ and a significant decrease in the concentration of CRP, but no change in TNF- $\alpha$ or IL-6. HOMA-IR was significantly reduced. Conclusions: The decrease in CRP level without changes in TNF- $\alpha$ or IL-6 concentrations after the low-calorie diet and balneological treatment, suggests that an essential amount of adipose tissue must be removed before proper adipocyte function is restored. The decrease in HOMA-IR indicates an improvement in insulin sensitivity, which is beneficial in obese patients.
\end{abstract}

Key words: Pro-inflammatory cytokines, Tumor necrosis factor- $\alpha$ (TNF- $\alpha$ ), Interleukin-6 (IL-6), Morbid obesity, C-reactive protein (CRP), Homeostasis model assessment-insulin resistance (HOMA-IR) doi: $10.1631 /$ jzus.B1400219

Document code: A

CLC number: R589.2

\section{Introduction}

Obesity, as a socio-economic issue, is rising in prevalence worldwide. According to the World Health Organization, in 20051.6 billion people were

\footnotetext{
* Project supported by the Nicolaus Copernicus University, Collegium Medicum in Bydgoszcz, Poland

(D) ORCID: Danuta ROŚĆ, http://orcid.org/0000-0002-2971-9882

(C) Zhejiang University and Springer-Verlag Berlin Heidelberg 2015
}

overweight and 400 million patients suffered from obesity (Szymocha et al., 2009). It is estimated that in North America almost two-thirds of the population are overweight, one-half of whom are obese (Switzer et al., 2013). Moreover, in Europe obesity affects $10 \%-25 \%$ of men and $10 \%-30 \%$ of women. Morbid obesity, defined by a body mass index (BMI) of $>40 \mathrm{~kg} / \mathrm{m}^{2}$, is observed in $3.1 \%$ of men and $6.7 \%$ of women in the USA (Drenick et al., 1980; Switzer et al., 2013). 
Next to genetic factors, environmental factors, especially changes in the lifestyle model towards less physical activity and an excess of high-energy food intake, are considered the main causes of obesity development. Clinical observations and numerous studies have confirmed a higher risk of hypertension, type 2 diabetes, cancers, hyperlipidemia, stroke, asthma, obstructive sleep apnea, and renal failure in association with obesity (Szymocha et al., 2009; Switzer et al., 2013).

Gregor and Hotamisligil (2011) considered chronic low-grade systemic inflammation a hallmark of obesity. The development of adipose tissue is characterized by enlarging adipocytes and an accumulation of macrophages, resulting in an increase in leptin and a decrease in adiponectin in the blood, and a release into the circulation of cytokines, such as interleukin-6 (IL-6) and tumor necrosis factor- $\alpha$ (TNF- $\alpha$ ), and chemokines, such as monocyte chemoattractant protein (MCP-1) (Cardillo et al., 2006; Gregor and Hotamisligil, 2011). The overexpression of TNF- $\alpha$ leads to insulin resistance, reduced lipoprotein lipase activity, and increased lipase activity dependent on hormone (Zahorska-Markiewicz et al., 2000). IL-6 stimulates the secretion of glucocorticoids, increasing the affinity of IL-6 receptors on liver cells. This, in turn, increases the production of acute phase proteins, including C-reactive protein (CRP), fibrinogen, plasminogen activator inhibitor type 1 (PAI-1), serum amyloid A, and von Willebrand factor (Gabay, 2006). The principal function of CRP is the activation of the complement system and initiation of the elimination of pathogens. CRP inhibits neutrophil adhesion to endothelial cells and reduces the formation of free radicals in neutrophils (Verma et al., 2004).

The first recommendation in the treatment of overweight or obese patients is lifestyle modification. A low-calorie diet (LCD) is the primary strategy in the treatment of obesity. It is characterized by generating an energy deficit that should be between 500 and $1000 \mathrm{kcal} / \mathrm{d}(1 \mathrm{kcal}=4.1868 \mathrm{~kJ})$. With a negative energy balance, there is possible a weight loss of 0.5 to $1 \mathrm{~kg} /$ week (Johansson et al., 2014). Specific health benefits after weight reduction were noted: a decrease in blood glucose and serum lipid levels, lower blood pressure, an increase in insulin sensitivity, and a reduction in the use of drugs (Jarosz and Grodowska, 2008). Weight loss, regardless of the dietary type, positively influences inflammation markers, de- creasing CRP and IL-6 levels (Clifton, 2003).

Weight loss via diet and physical activity may be supported by balneological treatment (BT), which is a natural therapeutic method involving bathing, drinking, and inhalation of natural mineral water, typically at a spa resort, and also including massage, mud-baths, relaxation, and some exercises in water (Gutenbrunner et al., 2010). The minerals absorbed through the skin relieve pain and decrease inflammation, thereby reducing swelling and muscle tension. Thus, obesity is a specific target of balneotherapy, which can have a positive effect (Oláh et al., 2011; Hanh et al., 2012).

A review of the literature shows that there have been few studies analyzing the role of inflammation in morbid obesity. The aim of this study was to evaluate selected markers of inflammation (i.e. CRP, TNF- $\alpha$, IL-6) and the degree of insulin resistance in patients with morbid obesity given a three-week LCD and BT.

\section{Materials and methods}

The study included 33 patients ( 25 females aged 28-69 years (mean age 46 years) and 8 males aged 20-56 years (mean age 43 years)) with morbid obesity. The criterion for the patients' eligibility for the study was a BMI of $>40 \mathrm{~kg} / \mathrm{m}^{2}$ and a lack of symptoms associated with acute or chronic inflammation. The mean duration of obesity was 22.4 years. The patients were under the care of the Clinic of Balneology and Physical Medicine in Ciechocinek, Poland.

A medical history interview conducted by a medical specialist revealed information about the general condition of the patients and the occurrence of co-existing diseases: 23 patients suffered from hypertension and 9 had impaired glucose tolerance, but none had overt diabetes. Twenty-eight patients had a family history of dyslipidemia and 12 a family history of diabetes. Among all the patients, 26 had taken hypertension drugs (angiotensin-converting enzyme (ACE) inhibitor drugs) and 4 had undergone anticoagulant therapy. The patients also had received statins and drugs inhibiting gastric acid secretion.

In all patients anthropometric parameters were measured including body weight, body shape, and fat content through the measurements of height, weight, and waist circumference. 
The study involved collection of data at two time points: before treatment (baseline) and three weeks after treatment. The patients were given instructions about the study protocol: during the three-week observation period they should adopt the same lifestyle. The subjects followed a LCD of $1000 \mathrm{kcal} / \mathrm{d}$ for $7 \mathrm{~d}$, a very $L C D$ of $400 \mathrm{kcal} / \mathrm{d}$ for $4 \mathrm{~d}$, then returned to the LCD until the end of the observation period. The menu was prepared by a professional nutritionist and meals were served at resort restaurants. The daily exercise program included $1 \mathrm{~h}$ of brisk walking and $45 \mathrm{~min}$ of morning gymnastics. Balneotherapy followed a three-week cycle comprising a mineral water bubble bath at $38{ }^{\circ} \mathrm{C}$ for $15 \mathrm{~min}$, mineral water pool exercises at $31^{\circ} \mathrm{C}$ for $40 \mathrm{~min}$, and a warm mud bath at $42{ }^{\circ} \mathrm{C}$ for $15 \mathrm{~min}$.

The evaluations of CRP, TNF- $\alpha$, IL- 6 , lipid profile, HOMA-IR, and fasting glucose, and the measurement of anthropometric parameters, were carried out before and $21 \mathrm{~d}$ after the treatment.

The control group consisted of 20 healthy volunteers ( 15 females and 5 males) with a mean age of 39 years and a BMI of $\leq 24.9 \mathrm{~kg} / \mathrm{m}^{2}$. Table 1 shows the clinical data of patients and the control group.

Venous blood $(4.5 \mathrm{ml})$ for tests of CRP, IL-6, and TNF- $\alpha$ was collected from patients into cooled tubes (Becton Dickinson Vacutainer ${ }^{\mathbb{B}}$ System, Plymouth, UK) containing $0.13 \mathrm{~mol} / \mathrm{L}$ trisodium citrate (the final blood-anticoagulant ratio was 9:1) after 30 min of rest between 7:30 a.m. and 9:30 a.m. after a 12 -h overnight fast. The blood samples were immediately mixed and centrifuged at $3000 \mathrm{~g}$ at $4{ }^{\circ} \mathrm{C}$ for $20 \mathrm{~min}$. The samples were frozen at $-20{ }^{\circ} \mathrm{C}$ until analysed, but were kept no longer than 6 months.

To determine CRP, IL- 6 , TNF- $\alpha$, insulin and lipid profiles, $4.5 \mathrm{ml}$ of blood was collected into a tube without anticoagulant after $30 \mathrm{~min}$ of rest between 7:30 a.m. and 9:30 a.m. after a 12-h overnight fast.. The sample was centrifuged at $3000 \mathrm{~g}$ for $20 \mathrm{~min}$ at $4{ }^{\circ} \mathrm{C}$ and subjected to further analytical procedures. To evaluate the fasting glucose, blood was sampled into a $4.5-\mathrm{ml}$ tube with sodium fluoride ethylenediaminetetraacetic acid (EDTA). The plasma was centrifuged at $2000 \mathrm{~g}$ for $10 \mathrm{~min}$ at $4{ }^{\circ} \mathrm{C}$ and subjected to further analytical procedures. The body fat measurement was made, and insulin resistance was calculated using the homeostasis model assessment: HOMA-IR= fasting glucose $(\mathrm{mmol} / \mathrm{L}) \times$ fasting insulin $(\mathrm{mU} / \mathrm{L}) / 22.5$.
The concentrations of CRP, IL- 6 , and TNF- $\alpha$ were assessed by enzyme-linked immuno sorbent assay (ELISA). The concentration of CRP was estimated with human CRP Instant ELISA (Bender MedSystem ${ }^{\circledR} \mathrm{GmbH}$, Vienna, Austria); IL-6 was determined using human IL-6 ELISA, (Bender MedSystem ${ }^{\circledR}$ GmbH, Vienna, Austria). The concentration of TNF- $\alpha$ was assayed using monkey TNF- $\alpha$ ELISA (Bender MedSystem ${ }^{\circledR} \mathrm{GmbH}$, Vienna, Austria). The parameters of the lipid profile, and concentrations of fasting glucose and insulin were recorded following specific tests using the Abbott Clinical Chemistry Analyzer ${ }^{\circledR}$ Architect c8000 (Abbott Diagnostics Europe, Wiesbaden, Germany).

Written informed consent was received from each participant before the study. The study was approved by the Bioethics Committee of Collegium Medicum in Bydgoszcz, Nicolaus Copernicus University, Toruń, Poland (No. KB138/2009).

Statistical analysis was performed using Statistica 9.0 software (StatStoft ${ }^{\circledR}$, Cracow, Poland). The Shapiro-Wilk test was used to assess the normality of distributions, which facilitated the use of Student's $t$-test; the mean and standard deviation (SD) were determined for each variable. The U-Mann-Whitney rank-sum test was used when the distribution was not normal. Parameters with values deviating from a normal distribution were described by the median, lower quartile (Q1), and upper quartile (Q3). To assess the correlation between the parameters, Spearman's rank coefficient was applied. $P$-values of $<0.05$ were considered significant.

\section{Results}

Table 1 shows the concentrations of CRP, TNF- $\alpha$, IL-6, and fasting glucose, the lipid profile, level of HOMA-IR, and anthropometric parameters in patients with morbid obesity, compared with those of the control group. There were significantly higher levels of CRP, TNF- $\alpha$, triglycerides (TG), fasting glucose, and HOMA-IR, and lower HDL cholesterol in the blood of obese subjects, compared with the control group. Moreover, significantly higher BMI, waist-hip ratio (WHR), body weight, and body fat were noted in patients with morbid obesity than in the control group. 
Table 2 shows the concentrations of CRP, TNF- $\alpha$, and IL-6, HOMA-IR, and anthropometric and selected laboratory parameters in the study group before and after the LCD and BT. A significant decrease in CRP levels was recorded. The mean weight of $122.5 \mathrm{~kg}$ in the study group decreased by $11.50 \mathrm{~kg}(9.4 \%)$ after three weeks of the LCD and BT, but the difference was not statistically significant. The treatment resulted in a significant decrease in total-cholesterol, LDLxcholesterol, HDL-cholesterol, and HOMA-IR. Figs. 1 and 2 show the significant changes in levels of CRP, IL- 6 , and TNF- $\alpha$ before and after the treatment.

Table 1 Comparison of the parameters in the study group and the control group

\begin{tabular}{lccc}
\hline \multicolumn{1}{c}{ Parameter } & Study group $(n=33)$ & Control group $(n=20)$ & $P$-value \\
\hline BMI $\left(\mathrm{kg} / \mathrm{m}^{2}\right)$ & $44.16 \pm 5.55$ & $22.06 \pm 1.79$ & 0.0001 \\
WHR & $0.93 \pm 0.06$ & $0.83 \pm 0.05$ & 0.0001 \\
Total-cholesterol $(\mathrm{mg} / \mathrm{dl})$ & $222.36 \pm 36.71$ & $224.40 \pm 36.10$ & 0.8446 \\
HDL-cholesterol $(\mathrm{mg} / \mathrm{dl})$ & $50.00(42.00 ; 56.00)$ & $71.00(57.00 ; 77.00)$ & 0.0001 \\
LDL-cholesterol $(\mathrm{mg} / \mathrm{dl})$ & $142.55 \pm 36.33$ & $146.68 \pm 40.67$ & 0.7065 \\
TG $(\mathrm{mg} / \mathrm{dl})$ & $119.00(100.00 ; 152.00)$ & $71.50(61.50 ; 84.00)$ & 0.0001 \\
Body weight $(\mathrm{kg})$ & $122.50(100.90 ; 137.00)$ & $59.50(56.50 ; 65.00)$ & 0.0001 \\
Body fat $(\%)$ & $51.68 \pm 6.70$ & $33.17 \pm 4.84$ & 0.0001 \\
Body fat $(\mathrm{kg})$ & $61.49 \pm 12.40$ & $20.18 \pm 3.45$ & 0.0000001 \\
Fasting glucose $(\mathrm{mg} / \mathrm{dl})$ & $93.00(88.00 ; 105.00)$ & $84.00(79.00 ; 91.00)$ & 0.0033 \\
CRP $(\mathrm{pg} / \mathrm{ml})$ & $1916.80(1025.40 ; 2070.64)$ & $548.20(285.04 ; 1438.68)$ & 0.0004 \\
TNF- $\alpha(\mathrm{pg} / \mathrm{ml})$ & $11.23 \pm 6.48$ & $6.20 \pm 5.67$ & 0.0092 \\
IL-6 $(\mathrm{pg} / \mathrm{ml})$ & $2.91(2.03 ; 3.64)$ & $2.91(2.32 ; 3.20)$ & 0.8113 \\
HOMA-IR & $3.66 \pm 2.74$ & $1.39 \pm 0.68$ & 0.0050 \\
\hline
\end{tabular}

Data are expressed as mean \pm SD or median (Q1; Q3)

Table 2 Effect of the treatment on the parameters identified in the patient group

\begin{tabular}{lccc}
\hline \multicolumn{1}{c}{ Parameter } & Before treatment $(n=33)$ & After treatment $(n=33)$ & $P$-value \\
\hline Body weight $(\mathrm{kg})$ & $122.50(100.90 ; 137.00)$ & $111.00(95.90 ; 131.00)$ & 0.1147 \\
BMI $\left(\mathrm{kg} / \mathrm{m}^{2}\right)$ & $44.16 \pm 5.55$ & $41.80 \pm 5.31$ & 0.0828 \\
WHR & $0.93 \pm 0.06$ & $0.92 \pm 0.06$ & 0.5724 \\
Total-cholesterol $(\mathrm{mg} / \mathrm{dl})$ & $222.36 \pm 36.71$ & $192.12 \pm 39.39$ & 0.0019 \\
HDL-cholesterol $(\mathrm{mg} / \mathrm{dl})$ & $50.00(42.00 ; 56.00)$ & $42.00(36.00 ; 46.00)$ & 0.0302 \\
LDL-cholesterol $(\mathrm{mg} / \mathrm{dl})$ & $142.55 \pm 36.33$ & $119.85 \pm 30.87$ & 0.0081 \\
CRP $(\mathrm{pg} / \mathrm{ml})$ & $1916.80(1025.40 ; 2070.64)$ & $1627.80(894.10 ; 1832.70)$ & 0.0106 \\
TNF- $\alpha(\mathrm{pg} / \mathrm{ml})$ & $11.23 \pm 6.48$ & $9.03 \pm 10.17$ & 0.8319 \\
IL-6 $(\mathrm{pg} / \mathrm{ml})$ & $2.91(2.03 ; 3.64)$ & $3.49(2.61 ; 4.36)$ & 0.1548 \\
HOMA-IR & $3.66 \pm 2.74$ & $2.71 \pm 1.56$ & 0.0050 \\
\hline
\end{tabular}

Data are expressed as mean \pm SD or median $(\mathrm{Q} 1 ; \mathrm{Q} 3)$

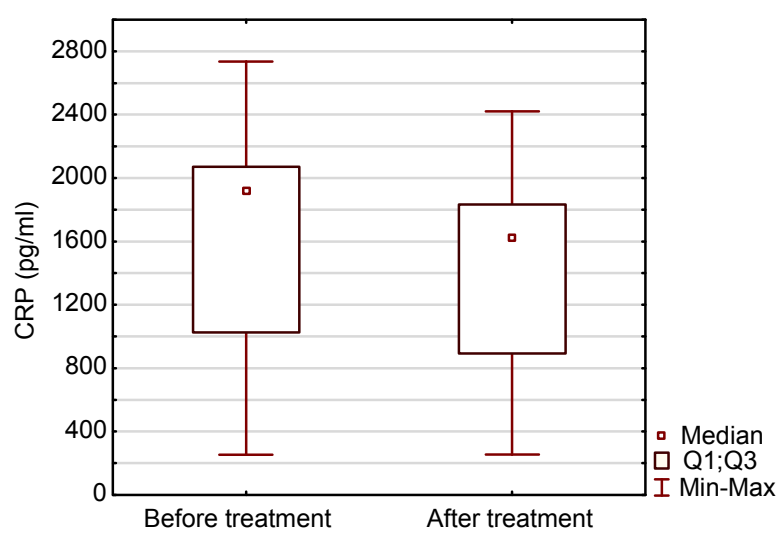

Fig. 1 Comparison of CRP level before and after the low-calorie diet and balneological treatment

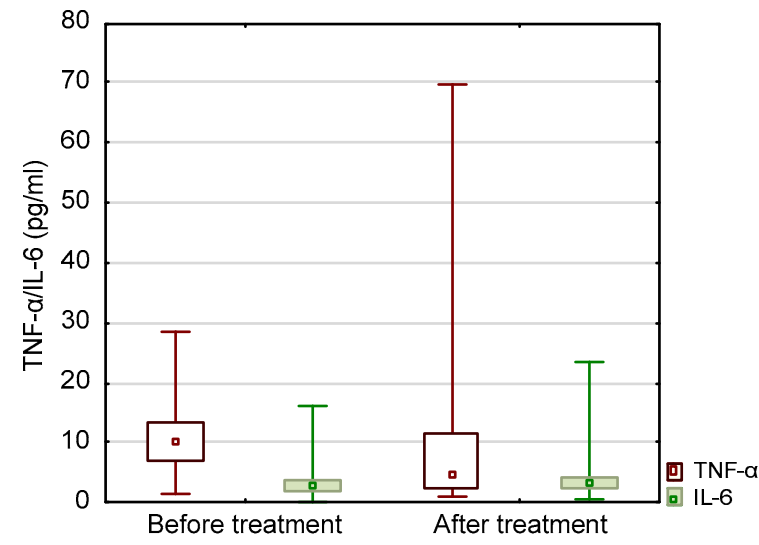

Fig. 2 Comparison of TNF- $\alpha$ and IL-6 levels before and after the low-calorie diet and balneological treatment 
Table 3 demonstrates the correlations between CRP, TNF- $\alpha$, IL- 6 and selected parameters in obese patients before the treatment. There was a significant positive correlation between CRP and BMI and serum TG, a positive correlation between TNF- $\alpha$ and body weight, and a negative correlation between IL-6 levels and HDL-cholesterol.

Table 3 Correlations between CRP, TNF- $\alpha$, IL-6 and anthropometric and biochemical parameters in patients with morbid obesity before the treatment

\begin{tabular}{|c|c|c|c|c|c|c|}
\hline \multirow{2}{*}{ Parameter } & \multicolumn{2}{|c|}{ CRP } & \multicolumn{2}{|c|}{ TNF- $\alpha$} & \multicolumn{2}{|c|}{ IL-6 } \\
\hline & $r$ & $P$ & $r$ & $P$ & $r$ & $P$ \\
\hline BMI & 0.4024 & 0.0274 & 0.2834 & 0.1099 & -0.226 & 0.2134 \\
\hline HDL-C & -0.0457 & 0.8104 & -0.2261 & 0.2056 & -0.358 & 0.0441 \\
\hline TG & 0.5963 & 0.0005 & 0.3058 & 0.0834 & -0.159 & 0.3824 \\
\hline BW & 0.0512 & 0.7881 & 0.3559 & 0.0420 & 0.064 & 0.7247 \\
\hline
\end{tabular}

HDL-C: HDL-cholesterol; BW: body weight

Table 4 shows correlations between CRP, TNF- $\alpha$, IL- 6 and anthropometric and biochemical parameters in patients with morbid obesity after the treatment. There were significant positive correlations between TNF- $\alpha$ and body fat, BMI, and fasting glucose after the treatment.

Table 4 Correlations between CRP, TNF- $\alpha$, IL-6 and anthropometric and biochemical parameters in patients with morbid obesity after the treatment

\begin{tabular}{|c|c|c|c|c|c|c|}
\hline \multirow{2}{*}{ Parameter } & \multicolumn{2}{|c|}{ CRP } & \multicolumn{2}{|c|}{ TNF- $\alpha$} & \multicolumn{2}{|c|}{ IL-6 } \\
\hline & $r$ & $P$ & $r$ & $P$ & $r$ & $P$ \\
\hline$\overline{\mathrm{BMI}}$ & 0.3125 & 0.0705 & 0.5339 & 0.0126 & -0.1243 & 0.5127 \\
\hline $\begin{array}{c}\text { Body fat } \\
(\%)\end{array}$ & 0.1512 & 0.5881 & 0.4975 & 0.0265 & -0.1014 & 0.6145 \\
\hline $\begin{array}{c}\text { Body fat } \\
(\mathrm{kg})\end{array}$ & 0.2456 & 0.3641 & 0.5158 & 0.0198 & 0.4889 & 0.6291 \\
\hline $\begin{array}{l}\text { Fasting } \\
\text { glucose }\end{array}$ & 0.0831 & 0.7001 & 0.7053 & 0.0003 & -0.0650 & 0.7326 \\
\hline
\end{tabular}

\section{Discussion}

The study demonstrated that, compared with the control group, in the blood of patients with morbid obesity, TNF- $\alpha$ and CRP levels were higher and accompanied by alterations in anthropometric parameters, a higher BMI and WHR, a higher body weight and body fat, and by fluctuations in the lipid profile including higher TG and lower HDL-cholesterol.
Moreover, higher fasting glucose and HOMA-IR levels were recorded compared with the control group.

CRP is a marker of inflammation, and an increased level of CRP is observed in metabolic diseases such as obesity, type 2 diabetes, and atherosclerosis (Czyżewska et al., 2012). The observed increase in CRP levels reported in patients with morbid obesity is consistent with the studies of Hofso et al. (2009), van Dielen et al. (2001), and Solá et al. (2009). In patients with morbid obesity there was a positive correlation between the concentration of CRP and BMI before the BT, which is in line with the results reported by Visser et al. (1999). These outcomes confirm the presence of low-grade inflammation and tissue damage in those patients.

Interestingly, in the current study the CRP level decreased, but no differences in TNF- $\alpha$ or IL- 6 concentrations were reported after the LCD and BT. Similar results were obtained by Vázquez et al. (2005) in patients with morbid obesity four months after bariatric surgery, which indicated that inflammatory pathways, including the TNF- $\alpha$ system and IL-6, remain activated. However, in 22 obese and 20 hypertensive patients subjected to BT with thermal water at $38^{\circ} \mathrm{C}$ in 15 sessions (each of 30-min duration), Oláh et al. (2011) observed a significant decrease in post-treatment CRP levels in a hypertensive group but not in obese subjects. Our results are inconsistent with those reported by Cardillo et al. (2006) who found no significant improvement in CRP levels of participants following either a low-carbohydrate diet or a conventional low-fat diet for 36 months. Likewise, in 67 severe or morbidly obese patients submitted to a 4-week very low-calorie diet followed by a lowcalorie diet for 2 months, Solá et al. (2009) found no changes in CRP, IL-6, or TNF- $\alpha$ levels after weight reduction (19.6\%). These divergent results might be due to the volume of weight reduction, the type of treatment (low-fat, low-carbohydrate, very lowcalorie diet, or bariatric surgery), or the duration of the observation period, which tended to differ in each study.

TNF- $\alpha$ is considered to be an important factor linking the pathophysiology of obesity with insulin resistance (Cardillo et al., 2006). Significantly higher levels of TNF- $\alpha$ in the blood of patients with morbid obesity recorded in the current study are consistent with the results reported by Solá et al. (2009) in 
patients with morbid obesity and by Goyal et al. (2012) in patients with severe obesity (BMI $>30 \mathrm{~kg} / \mathrm{m}^{2}$ ) and type 2 diabetes. Cardillo et al. (2006) studied 26 low-fat and 27 low-carbohydrate participants with a BMI of $>35 \mathrm{~kg} / \mathrm{m}^{2}$ and found no differences in the concentration of TNF- $\alpha$ after 6 and 36 months of the observation period, independent of the diet regimen. Xydakis et al. (2004) found no differences in TNF- $\alpha$ concentrations among obese individuals (56 women and 24 men with a BMI of $\left.>(38.3 \pm 0.7) \mathrm{kg} / \mathrm{m}^{2}\right)$ after 4-6 weeks of weight loss induced by a very low calorie diet. Perhaps the metabolic stress results from a relative starvation effect on the inflammatory response (Vázquez et al., 2005; Solá et al., 2009). However, Zahorska-Markiewicz et al. (2008) reported an impact of weight loss on the level of TNF- $\alpha$ in obese women. After three months of treatment based on a $1000 \mathrm{kcal} / \mathrm{d}$ diet and increased physical activity, they observed a significant decrease in TNF- $\alpha$.

The current study demonstrated a positive correlation between TNF- $\alpha$ and body weight before BT, and also between TNF- $\alpha$ and body fat, BMI, and fasting plasma glucose after the treatment. The indication of a strong connection between TNF- $\alpha$ and body fat in the obese patients is indirect evidence that this cytokine originates from adipocytes.

Visceral adipose tissue is considered a significant source of IL- 6 secreted under the influence of TNF- $\alpha$ (Cottam et al., 2004). Increased levels of IL-6 were found in the blood of patients with morbid obesity (Solá et al., 2009), in patients with type 2 diabetes accompanied by obesity (Goyal et al., 2012), and in patients with type 2 diabetes with accompanying albuminuria (Czyżewska et al., 2012). An effect of weight loss on serum IL-6 in obese patients undergoing weight reduction was observed by OlszaneckaGlinianowicz et al. (2011). After three months of therapy they reported a 5\% weight reduction and a reduction in IL- 6 concentration. Also, after 5 years the concentration of IL- 6 was significantly lower than baseline values. However, in the present study, there were no significant differences in IL-6 among patients with morbid obesity, compared with the control group and after the treatment. These divergent results may be linked to polymorphism for IL-6. Gene polymorphism for IL-6 has been observed in impaired hepatic lipid metabolism and insulin resistance (Czyżewska et al., 2012).
In a study by Bataille and Klein (1992) there was a positive correlation between IL-6 and BMI, WHR, blood glucose and insulin levels. The present study revealed a significant negative correlation between HDL-cholesterol and IL-6, which confirms the association of IL- 6 with dyslipidemia. The mechanism of the effect of IL- 6 on the metabolism of carbohydrates and lipids involves the inhibition of the activity of lipoprotein lipase (LPL), stimulating lipolysis, which is accompanied by the accumulation of TG and increased levels of free fatty acids (FFA) (Solá et al., 2009).

The absence of differences in TNF- $\alpha$ and IL-6 indicates permanent adipocyte abnormalities in morbidly obese patients despite a rapid weight reduction. However, an essential amount of adipose tissue must be lost before proper adipocyte function is restored (Xydakis et al., 2004).

In the present study, high HOMA-IR in patients with morbid obesity was the evidence of their insulin resistance. However, a short-term LCD and BT improved insulin sensitivity in obese subjects. This was confirmed by the return of HOMA-IR levels to normal values.

\section{Conclusions}

A decrease in CRP levels, but no differences in TNF- $\alpha$ or IL- 6 concentrations reported after the LCD and BT, suggests that an essential amount of adipose tissue must be removed before proper adipocyte function is restored. Numerous correlations between TNF- $\alpha$ and CRP and the parameters of carbohydrate and lipid metabolism indicate an important role of inflammation in the pathogenesis of metabolic abnormalities in obesity. Short-term weight reduction decreases the level of HOMA-IR, indicating an improvement in insulin sensitivity, which is beneficial in obese patients.

\section{Compliance with ethics guidelines}

Danuta ROŚĆ, Przemysław ADAMCZYK, Joanna BOINSKA, Robert SZAFKOWSKI, Irena PONIKOWSKA, Katarzyna STANKOWSKA, Barbara GÓRALCZYK, and Barbara RUSZKOWSKA-CIASTEK declare that they have no conflict of interest.

All procedures followed were in accordance with the ethical standards of the responsible committee on human 
experimentation (institutional and national) and with the Helsinki Declaration of 1975, as revised in 2008 (5). Informed consent was obtained from all patients for being included in the study. Additional informed consent was obtained from all patients for whom identifying information is included in this article.

\section{References}

Bataille, R., Klein, B., 1992. C-reactive protein levels as a direct indicator of interleukin-6 levels in humans in vivo. Arthritis Rheum., 35(8):982-984. [doi:10.1002/art.178 0350824]

Cardillo, S., Seshadri, P., Iqbal, N., 2006. The effects of a low-carbohydrate versus low-fat diet on adipocyto-kines in severely obese adults: three-year follow-up of a randomized trial. Eur. Rev. Med. Pharmacol. Sci., 10: 99-106.

Clifton, P.M., 2003. Diet and C-reactive protein. Curr. Atheroscler. Rep., 5(6):431-436. [doi:10.1007/s11883-0030032-z]

Cottam, D.R., Mattar, S.G., Barinas-Mitchel, E., et al., 2004. The chronic inflammatory hypothesis for the morbidity associated with morbid obesity: implications and effects of weight loss. Obes. Surg., 14(5):589-600. [doi:10.1381/ 096089204323093345]

Czyżewska, J., Wasilewska, K., Kamińska, J., et al., 2012. Assess the impact of concentrations of inflammatory markers: IL-6, CRP in the presence of albuminuria in patients with type 2 diabetes. Pol. Merk. Lek., 32(188): 98-102 (in Polish).

Drenick, E.J., Bale, G.S., Seltzer, F., et al., 1980. Excessive mortality and causes of death in morbidly obese men. $J A M A$, 243(5):443-445. [doi:10.1001/jama.243.5.443]

Gabay, C., 2006. Interleukin-6 and chronic inflammation. Arthritis. Res. Ther., 8(Suppl. 2):S3. [doi:10.1186/ar1917]

Goyal, R., Faizy, A.F., Siddiqui, S.S., et al., 2012. Evaluation of TNF- $\alpha$ and IL- 6 levels in obese and non-obese diabetics: pre- and postinsulin effects. N. Am. J. Med. Sci., 4(4):180-184. [doi:10.4103/1947-2714.94944]

Gregor, M.F., Hotamisligil, G.S., 2011. Inflammatory mechanisms in obesity. Annu. Rev. Immunol., 29(1):415-445. [doi:10.1146/annurev-immunol-031210-101322]

Gutenbrunner, C., Bender, T., Cantista, P., et al., 2010. A proposal for a worldwide definition of health resort medicine, balneology, medical hydrology and climatology. Int. J. Biometeorol., 54(5):495-507. [doi:10.1007/s00484010-0321-5]

Hanh, T., Serog, P., Fauconnier, J., et al., 2012. One-year effectiveness of a 3-week balneotherapy program for the treatment of overweight or obesity. Evid. Based Complement. Alternat. Med., 2012:150839. [doi:10.1155/ 2012/150839]

Hofso, D., Ueland, T., Hager, H., et al., 2009. Inflammatory mediators in morbidly obese subjects: associations with glucose abnormalities and changes after oral glucose. Eur. J. Endocrinol., 161(3):451-458. [doi:10.1530/EJE-09-0421]
Jarosz, M., Grodowska, A., 2008. Obesity treatment. Fam. Med. Prim. Care Rev., 10(4):1361-1366 (in Polish).

Johansson, K., Neovius, M., Hemmingsson, E., 2014. Effects of anti-obesity drugs, diet, and exercise on weight-loss maintenance after a very-low-calorie diet or low-calorie diet: a systematic review and meta-analysis of randomized controlled trials. Am. J. Clin. Nutr., 99(1):14-23. [doi:10.3945/ajen.113.070052]

Oláh, M., Koncz, Á., Fehér, J., et al., 2011. The effect of balneo-therapy on antioxidant, inflammatory, and metabolic indices in patients with cardiovascular risk factors (hypertension and obesity) - a randomised, controlled, follow-up study. Contemp. Clin. Trials, 32(6):793-801. [doi:10.1016/j.cct.2011.06.003]

Olszanecka-Glinianowicz, M., Chudek, J., Kocełak, P., et al., 2011. Body fat changes and activity of tumor necrosis factor $\alpha$ system - a 5-year follow-up study. Metabolism, 60(4):531-536. [doi:10.1016/j.metabol.2010.04.023]

Solá, E., Jover, A., López-Ruiz, A., et al., 2009. Parameters of inflammation in morbid obesity: lack of effect of moderate weight loss. Obes. Surg., 19(5):571-576. [doi:10. 1007/s11695-008-9772-8]

Switzer, N., Mangat, H., Karmali, S., 2013. Current trends in obesity: body composition assessment, weight regulation, and emerging techniques in managing severe obesity. $J$. Interv. Gastroenterol., 3(1):34-36. [doi:10.7178/jig.106]

Szymocha, M., Bryła, M., Maniecka-Bryła, I., 2009. The epidemic of obesity in the 21st century. Zdr. Publ., 119:207-212 (in Polish).

van Dielen, F.M.H, van't Veer, C., Schols, A.M., et al., 2001. Increased leptin concentrations correlate with increased concentrations of inflammatory markers in morbidly obese individuals. Int. J. Obes. Relat. Metab. Disord., 25(12):1759-1766. [doi:10.1038/sj.ijo.0801825]

Vázquez, L.A., Pazos, F., Berrazueta, J.R., et al., 2005. Effects of changes in body weight and insulin resistance on inflammation and endothelial function in morbid obesity after bariatric surgery. J. Clin. Endocrinol. Metab., 90(1): 316-322. [doi:10.1210/jc.2003-032059]

Verma, S., Szmitko, P.E., Yeh, E.T.H., 2004. C-reactive protein. Circulation, 109(16):1914-1917. [doi:10.1161/01. CIR.0000127085.32999.64]

Visser, M., Bouter, L.M., McQuillan, G.M., et al., 1999. Elevated $\mathrm{C}$-reactive protein levels in overweight and obese adults. JAMA, 282(22):2131-2135. [doi:10.1001/jama. 282.22.2131]

Xydakis, A.M., Case, C.C., Jones, P.H., et al., 2004. Adiponectin, inflammation, and the expression of the metabolic syndrome in obese individuals: the impact of rapid weight loss through caloric restriction. J. Clin. Endocrinol. Metab., 89(6):2697-2703. [doi:10.1210/jc. 2003-031826]

Zahorska-Markiewicz, B., Janowska, J., Olszanecka-Glinianowicz, M., et al., 2000. Serum concen-trations of TNF- $\alpha$ and soluble TNF- $\alpha$ receptors in obesity. Int. J. Obes. Relat. Metab. Disord., 24(11):1392-1395. [doi:10.1038/sj.ijo. 
0801398]

Zahorska-Markiewicz, B., Olszanecka-Glinianowicz, M., Janowska, J., et al., 2008. The effect of weight loss on serum concentrations of FAS and tumour necrosis factor $\alpha$ in obese women. Endokrynol. Pol., 59:19-22 (in Polish).

\section{中文概要}

题 目: 病态肥胖患者在接受治疗体重减少后 $\mathrm{C}$ 反应蛋 白、肿瘤坏死因子 $\alpha$ 和白细胞介素 -6 的水平变化

目 的：评估病态肥胖患者在低热量饮食和浸浴治疗前 后, C 反应蛋白 $(\mathrm{CRP}) 、$ 肿瘤坏死因子 $\alpha(\mathrm{TNF}-\alpha)$ 、 白细胞介素-6（IL-6）以及胰岛素抵抗指数
(HOMA-IR) 的水平变化。

创新点: 研究炎症反应对病态肥胖的影响。

方 法: 本研究包括 33 个病例和 20 个正常对照, 对治疗 前后的 CRP、IL-6、TNF- $\alpha$ 、血脂谱、HOMA-IR 以及空腹血糖水平进行评估。

结 论: 与对照组相比, 低热量饮食和浸浴治疗后, 病态 肥胖患者的 CRP 水平显著降低, 而 TNF- $\alpha$ 和 IL-6 的水平却没有显著变化, 这表明脂肪细胞的正常 功能恢复之前必须先去除一定量的脂肪组织。 HOMA-IR 水平的降低说明对胰岛素的敏感性有 所提高, 这有利于肥胖患者的治疗。

关键词: 促炎性细胞因子; 肿瘤坏死因子 $\alpha$; 白细胞介素- 6 ; $\mathrm{C}$ 反应蛋白; 病态肥胖症; 胰岛素抵抗指数 